\title{
The reversed-flow medio-distal fasciocutaneous island thigh flap: anatomic basis and clinical applications
}

\author{
F.T. Ballmer ${ }^{1}$ and A.C. Masquelet ${ }^{2}$ \\ ${ }^{1}$ Department of Orthopaedic Surgery, University of Berne, Inselspital, CH-3010 Berne, Switzerland \\ ${ }^{2}$ Service de Chirurgie Orthopédique et Réparatrice, Hôpital Aviceme, 125, route de Stalingrad, F-93000 Bobigny, France
}

Summary: A new fasciocutaneous reversed-flow island flap of the thigh is presented which is independent of the presence of perfused blood vessels below the level of the knee joint-line. The pedicle, which is supplied by the proximal genicular anastomotic network, consists of the osteoarticular branch $(\mathrm{OAB})$ and concomitant veins of the descending genicular artery. Based on cadaver dissections the $\mathrm{OAB}$ arose in $23 / 30$ specimens $(77 \%)$ together with the saphenous artery (SA). In 2/30 specimens $(7 \%)$ the $\mathrm{OAB}$ originated directly from the superficial femoral artery and in 1/30 specimens $(3 \%)$ the $\mathrm{OAB}$ was absent. The OAB gave off one to three cutaneous branches to the overlying skin in $26 / 30$ specimens $(87 \%)$. We were able to elevate a flap on the osteoarticular branch alone in $57 \%$. Additional length could be added to the pedicle in $33 \%$ by including the most proximal part of the saphenous artery together with its first cutaneous branch. Thus, in $90 \%$ of the dissections a reversed-flow island flap could be raised which reached the proximal half of the

Correspondence to: F.T. Ballmer leg, the knee and the most distal part of the thigh. We report our early clinical experience.

\section{Le lambeau fascio-cutané médio-distal de la cuisse à flux inversé. Bases anatomiques et applications cliniques}

Résumé : Un nouveau lambeau fasciocutané en îlot de la cuisse à flux inversé est présenté, dont la caractéristique est d'être indépendant de la présence de vaisseaux sanguins perfusés au-dessous du niveau de l'interligne articulaire du genou. Le pédicule est constitué par le réseau anastomotique proximal du genou centré sur le rameau ostéo-articulaire (ROA) de l'artère descendante du genou (ADG) et ses veines satellites. Ce ROA a été étudié sur des dissections cadavériques, il naissait 23 fois sur $30(77 \%)$ d'un tronc commun avec l'artère saphène (AS), dans 2 cas sur 30 (7\%) il naissait directement de l'artère fémorale superficielle, et dans 1 cas sur $30(3 \%)$ il était absent. Le ROA abandonnait 1 à 3 branches cutanées aux téguments adjacents sur 26 des 30 spécimens ( $87 \%$ ). Il fut possible de lever un lambeau centré sur le ROA seul dans $57 \%$ des cas. Il est possible d'allonger le pédicule en incluant la partie la plus proximale de l'artère saphène et sa première branche cutanée dans $33 \%$ des cas. En recourant ou non à cet artifice, sur 90\% des dissections, il aurait été possible de lever un lambeau en îlot à flux inversé qui aurait atteint la partie proximale de la jambe, le genou et la partie le plus distale de la cuisse. Nos premiers cas cliniques sont présentés.

Key words: Fascio-cutaneous flap Lower limb - Descending genicular artery - Osteoarticular branch

Soft tissue coverage of defects around the knee remains a reconstructive challenge. Muscular or fasciocutaneous flaps from the calf are not always available, particularly if there has been previous trauma, utilization, or in through-knee and especially below-knee amputations. Various procedures for these difficult situations, including the distally based vastus lateralis muscle flap [13], the vastus medialis muscle as a rotation flap [2] or as advancement flap [15], the popliteo-posterior thigh fasciocutaneous island flap [12], the lower posterolateral thigh flap [9], crossleg flaps [3] and free flaps [7] have been described to accomplish this end. Other options are the reversed-flow saphenous 
island flap [16], the saphenous posteromedial cutaneous island thigh flap and the saphenous superomedial cutaneous island leg flap [5], the medial septocutaneous island thigh flap [4], the sartorius myocutaneous island flap [14], the reversed flow saphenous island flap based on the medial inferior genicular a. [17], and the adipofascial flap based on the saphenous a. [10]. Inspired by a previous report by Hertel and Masquelet [6], describing a reversed-flow medial knee osteoperiosteal flap, we present an anatomic study and clinical experience of a new skin flap for closure of soft tissue defects around the knee and proximal half of the leg. This flap is a fasciocutaneous island flap and is harvested from the medial aspect of the lower half of the thigh. It is supplied by reversed-flow in the osteoarticular branch of the descending genicular a., thus being independent of the presence of perfused blood vessels below the level of the knee joint-line.

\section{Material and methods}

The anatomic study was carried out on 15 fresh cadavers ( 30 dissections) of both sexes, and the ages ranged from the fifth to the ninth decade. Both legs were injected with colored neoprene latex via the femoral a., and dissections were carried out after 2 days. Technical details of the dissection are described in the section. "Flap design and operative procedure". The vascular anatomy of the descending genicular a. (DGA) was studied with emphasis on the different combinations of its branches (the osteoarticular branch $(\mathrm{OAB})$, the saphenous a. (SA) and the muscular branch (MB)). Special attention was given to the presence of cutaneous branches arising from the $\mathrm{OAB}$ and to anastomoses of the latter with the arterial anastomotic circle of the knee. The genicular anastomoses are formed by the medial and lateral superior genicular, medial and lateral inferior genicular, middle genicular, anterior and posterior tibial recurrent, descending branch of the lateral circumflex femoral and circumflex fibular aa. $[8,18]$.

The following data were recorded:

a) the distances between the medial joint-line of the knee and the origins of the DGA, OAB, SA and MB, b) the diameter at their origin of the DGA, OAB, SA and MB,

c) the length of the DGA before its division,

d) the number and diameter at their origins of the cutaneous branches of the $\mathrm{OAB}$,

e) the distance between the medial joint-line of the knee and the origin of the cutaneous branches of the $\mathrm{OAB}$,

f) the pedicle lengths of two different vascular patterns (ie $\mathrm{OAB}$ alone and $\mathrm{OAB}+\mathrm{SA}$ ).

Clinical experience includes two patients with soft tissue defects around the knee.

\section{Results}

Anatomic study

\section{Descending genicular a. (DGA)}

The distal superficial femoral a. (SFA) or the proximal popliteal a. gave off three vascular axes: the $\mathrm{OAB}$, the $\mathrm{SA}$ and the $M B$, each accompanied by two venae comitantes. When two or three of the above mentioned arteries arose from a common trunk, the latter was called the DGA [6]. In 27/30 specimens (90\%) a DGA was found. The DGA arose from the SFA at an average of $14 \mathrm{~cm}$ (range $18.5-11.5 \mathrm{~cm}$ ) above the medial joint line. Its average diameter at its origin measured $2.0 \mathrm{~mm}$ (range $1.5-2.6 \mathrm{~mm}$ ). Within $1.6 \mathrm{~cm}$ of its origin (range $0.2-$ $3.5 \mathrm{~cm}$ ) it divided into its branches. The combinations of vessels forming the DGA and their frequency are listed in Table 1.

\section{Osteoarticular branch $(O A B)$}

The $\mathrm{OAB}$ arose in $23 / 30$ specimens $(77 \%)$ together with the $\mathrm{SA}(\mathrm{OAB}+$ $\mathrm{SA}+\mathrm{MB}$ and $\mathrm{OAB}+\mathrm{SA})$. In 2/30 specimens $(7 \%)$ the $\mathrm{OAB}$ originated directly from the SFA. In $1 / 30(3 \%)$ the $\mathrm{OAB}$ was absent. The $\mathrm{OAB}$ arose at an average of $12 \mathrm{~cm}$ (range $10-18 \mathrm{~cm}$ ) above the medial joint-line. Its mean diameter at its point of origin was $1.3 \mathrm{~mm}$ (range $0.6-2.0 \mathrm{~mm}$ ). The $\mathrm{OAB}$ ran in a distal direction on the posterior surface of the medial intermuscular septum alongside the adductor magnus tendon. In $16 / 30$
Table 1. Combinations of vessels forming the descending genicular a. (DGA) and their frequency $(\mathrm{OAB}=$ osteoarticular branch, $\mathrm{SA}=$ saphenous a., $\mathrm{MB}=$ muscular branch )

\begin{tabular}{ll}
\hline $\mathrm{OAB}+\mathrm{SA}+\mathrm{MB}$ & $11 / 30(37 \%)$ \\
$\mathrm{OAB}+\mathrm{SA}$ & $12 / 30(40 \%)$ \\
$\mathrm{OAB}+\mathrm{MB}$ & $4 / 30(13 \%)$ \\
No DGA & $3 / 30(10 \%)$ \\
\hline
\end{tabular}

Table 2. Numbers of cutaneous branches arising from the $\mathrm{OAB}$ per dissected specimen ( ${ }^{\mathrm{a}}$ including one specimen lacking an $\mathrm{OAB}$ )

\begin{tabular}{cc}
\hline $\begin{array}{l}\text { No. of cutaneous } \\
\text { branches }\end{array}$ & No. of specimens \\
\hline 3 & $2 / 30(7 \%)$ \\
2 & $9 / 30(30 \%)$ \\
1 & $15 / 30(50 \%)$ \\
0 & $4 / 30(13 \%)^{\mathrm{a}}$ \\
\hline
\end{tabular}

specimens $(53 \%)$ the $\mathrm{OAB}$ divided into a medial and a lateral branch after having reached the medial femoral condyle, and in the remaining cases it divided more proximally. The terminal vessels of the lateral branch, spreading over the medial femoral condyle, constantly anastomosed with the genicular anastomoses, ie the medial superior genicular a. and, in many cases, through a well-developed anterior anastomosis with the lateral superior genicular a. The medial branch of the $\mathrm{OAB}$ ran distally in front of the medial collateral ligament, crossing the joint line and anastomosing with the inferior genicular anastomoses, primarily with the medial inferior genicular a. The $\mathrm{OAB}$ gave off one to three cutaneous branches to the overlying skin in $26 / 30$ specimens $(87 \%)$. For numbers of cutaneous branches per dissected specimen see Table 2. The mean diameter of the cutaneous branches at their origin was $0.6 \mathrm{~mm}$ (range $0.2-0.9 \mathrm{~mm}$ ). They arose between 3 and $14 \mathrm{~cm}$ above the medial joint-line. The cutaneous branches bifurcated into ascending and descending branches, which formed a vascular arcade with the next ascending branch.

Saphenous a. (SA)

The origin of the SA was at an average of $12.5 \mathrm{~cm}$ (range $9.5-19 \mathrm{~cm}$ ) above the medial joint-line. Its mean diameter at its source was $1.2 \mathrm{~mm}$ (range $0.7-1.8 \mathrm{~mm}$ ). 
When originating in the adductor canal, it pierced the aponeurotic roof and came to lie in the loose fascial space bounded by the sartorius $m$. superficially, the adductor magnus tendon posteriorly, and the vastus medialis $\mathrm{m}$. anterolaterally. It ran distally in this space, finally passing between the sartorius and gracilis $\mathrm{mm}$. to reach the medial side of the leg. The SA gave constantly branches to the overlying skin and to the sartorius $m$.

\section{Muscular branch (MB)}

The MB was not part of the pedicle of the flap but data are listed because of its anatomic proximity. It arose at an average of $12 \mathrm{~cm}$ (range $7-18.5 \mathrm{~cm}$ ) above the medial joint-line and entered the vastus medialis $\mathrm{m}$. after an average distance of $0.5 \mathrm{~cm}$. Its mean diameter at the origin was $1.4 \mathrm{~mm}$ (range $0.6-2.5 \mathrm{~mm}$ ). Additional muscular branches to the vastus medialis $\mathrm{m}$. may originate from the DGA, OAB or SFA.

\section{Venous drainage}

In general, the venae comitantes of the three arterial axes joined to form the descending genicular $v$. which unified with the superficial femoral $v$. The venae comitantes occasionally drained as two or three separate branches directly into the femoral v.

\section{Patterns and lengths of the pedicles}

Several factors determined the patterns and lengths of the pedicle: the localization of the origin of a reliable cutaneous branch from the $O A B$ and the presence of a common trunk formed by the $\mathrm{OAB}$ and SA, as well as the very rare possibility of absence of the $\mathrm{OAB}$.

A. The OAB was present and gave off a reliable cutaneous branch near its origin (Fig. 1). This pattern was encountered in $17 / 30$ specimens (57\%). With this pattern the presence of a common trunk (i.e. $\mathrm{OAB}+\mathrm{SA}$ ) is irrelevant, and the procedure is straightforward. After ligature of the $\mathrm{OAB}$ and its venae comitantes proximal to its cutaneous branch, a reversed-flow fasciocutaneous island flap could be raised tracing the vascular axis distally. This flap could be rotated on a

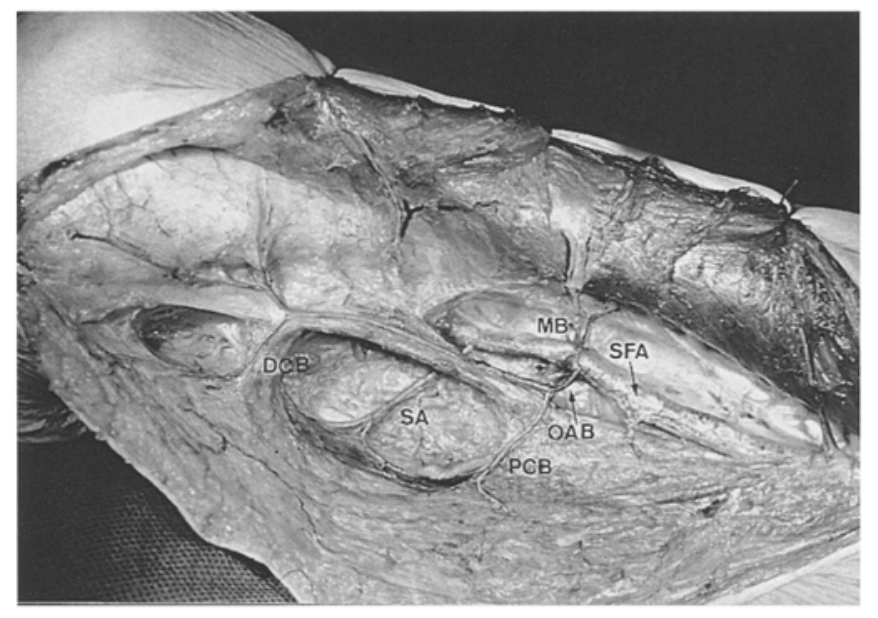

Fig. 1

Medial view of right medio-distal thigh (on the right, proximal thigh; on the left, knee joint and proximal calf): The osteoarticular branch $(O A B)$ gives off a good proximal $(P C B)$ and distal cutaneous branch $(D C B)$, A reversed-flow island flap can be raised after ligature of the $O A B$ proximal to the proximal cutaneous branch. The saphenous a. (SA) and muscular branch $(M B)$ arise directly from the superficial femoral a. (SFA)
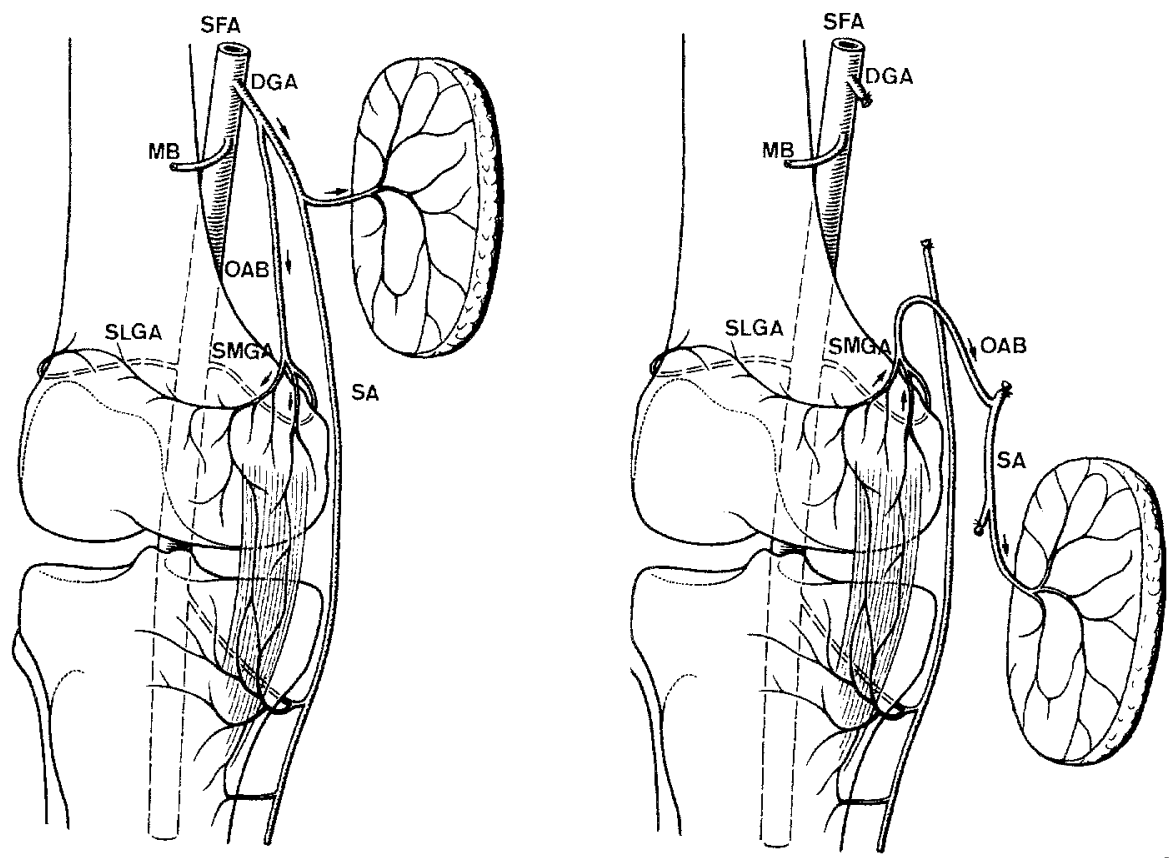

a

b

Fig. $2 a, b$

a The $O A B$ gives off no cutaneous branch but arises from a common trunk (ie $D G A$ ) with the SA which constantly gives off cutaneous branches. Note the anastomoses of the $O A B$ with the superomedial (SMGA) and superolateral genicular aa. ( $S L G A$ ). $\mathbf{b}$ A reversed-flow island flap based on the $O A B$ can be raised after ligature of the common trunk (i.e. $D G A$ ) and of the SA distal to its cutaneous branch. This pattern lengthens the pedicle.

pivotal point in the area of the internal femoral condyle, where the vessels anastomosed constantly with the genicular anastomoses. Both the arterial supply and the venous drainage were retrograde in this situation. The mean pedicle length was $14 \mathrm{~cm}$ (range $10-15.5 \mathrm{~cm}$ ).

B. The $\mathrm{OAB}$ was present and gave off a distal cutaneous branch, or the cutaneous branch was absent (Fig. 2a), but the $\mathrm{OAB}$ arose from a common trunk (ie DGA) with the SA. The latter gave off constant cutaneous branches proximal to the joint-line $[4,5]$. This pattern was found in $10 / 30$ specimens (33\%). Note that the origin of a cutaneous branch from the $\mathrm{OAB}$ was regarded as distal when originating in the distal half of the distance between the origin of the $\mathrm{OAB}$ and the joint-line. The SA and its venae comitantes were ligated proximal to the junction with the OAB (ie DGA) and distal to the origin of the cutaneous branch (from the SA). A reversed-flow island flap could then be raised based on the $\mathrm{OAB}$ and $\mathrm{SA}$ with the constant cutaneous 


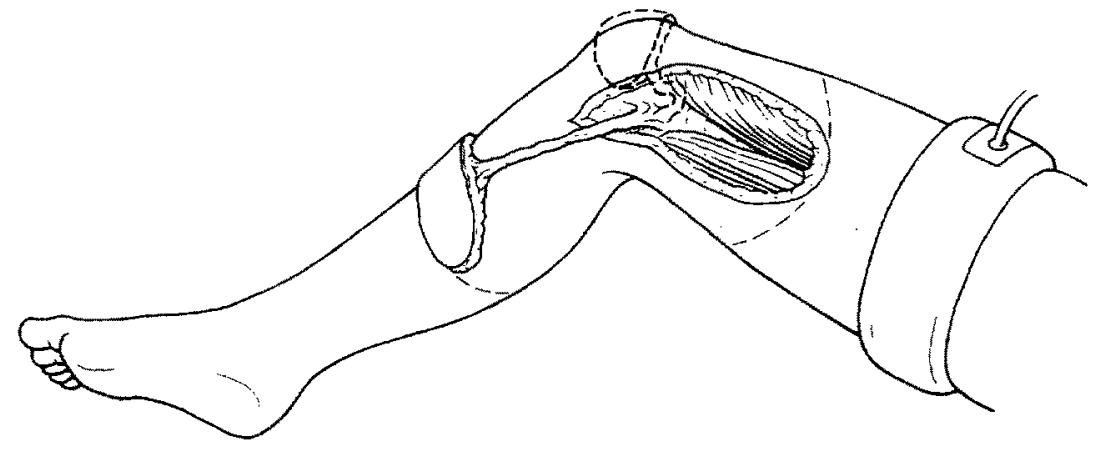

Fig. 3

Arc of rotation: the proximal half of the leg, the knee and the most distal part of the thigh can be reached

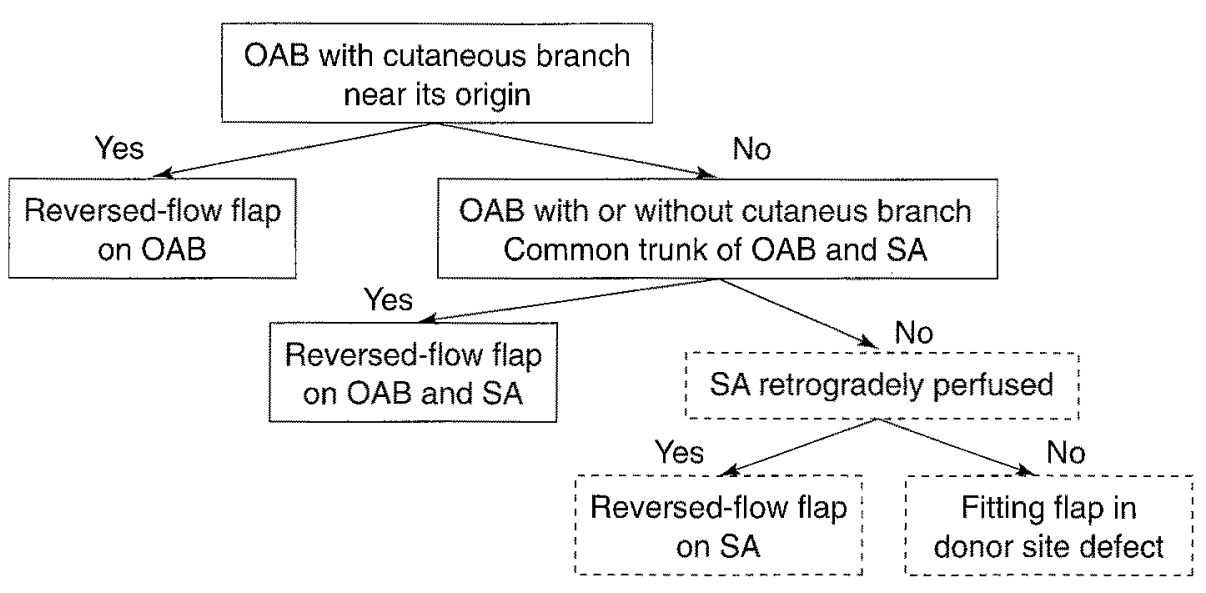

Fig. 5

Algorithm of intraoperative decision-making

branch of the latter (Fig. 2b). The arterial flow and venous drainage were retrograde in the OAB, and orthograde in the SA and in its cutaneous branch. Choosing the pivotal point again in the region of the internal femoral condyle, the arterial supply and venous drainage were the same as described above. The mean pedicle length was $17 \mathrm{~cm}$ (range $13.5-18 \mathrm{~cm}$ ). Note that the mean pedicle length was $3 \mathrm{~cm}$ greater in this pattern, as the length of the SA from its origin to its cutaneous branch was added to the length of the $O A B$. With patterns $A$ and $B$ the proximal half of the leg could easily be reached by adding a flap size of at least $15 \mathrm{x}$ $5 \mathrm{~cm}$. Furthermore, the arc of rotation of the flap allowed coverage of defects around the knee and the most distal part of the thigh (Fig. 3).
C. The $\mathrm{OAB}$ was present and gave off a distal cutaneous branch, or the cutaneous branch was absent but the OAB formed no common trunk with the SA. The possible presence of a common trunk formed by the $\mathrm{OAB}$ and $\mathrm{MB}$ was not helpful for adding extra length to the pedicle due to the anatomic course and shortness of the MB. Finally, very rarely the $\mathrm{OAB}$ was absent. One of the aforementioned patterns was found in $3 / 30$ specimens ( $10 \%$ ), and a flap could not be raised as described in section $\mathrm{A}$ or $\mathrm{B}$. If a retrograde circulation of the saphenous a., fed by perforating branches of the posterior tibial a. and the medial inferior genicular a., was present, it was possible to switch to a reversed-flow saphenous island flap as a salvage procedure (Fig. 4) $[4,5,16,17]$.

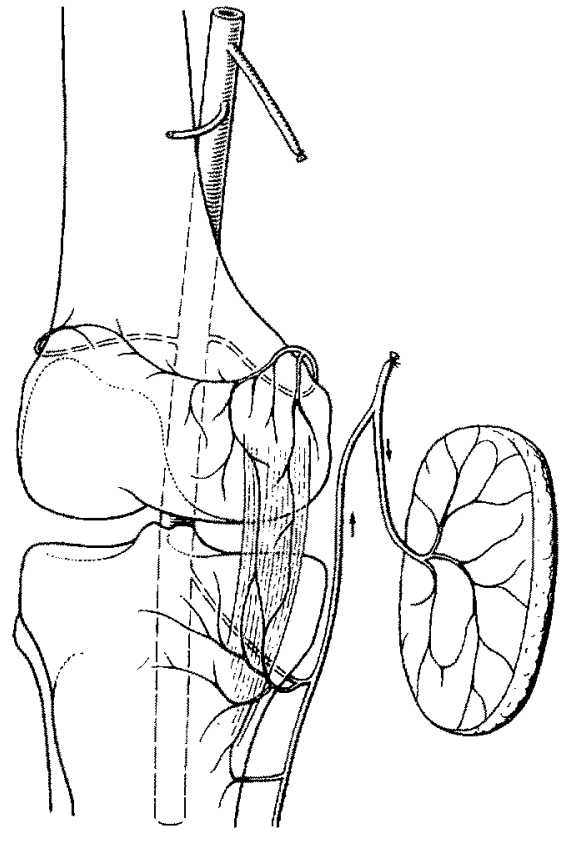

Fig. 4

Reversed-flow saphenous island flap as alternative which is only possible if the saphenous a is retrogradely perfused

The algorithm of intraoperative decision-making is summarized in Fig. 5.

\section{Flap design and operative procedure}

The patient is supine with a wedge under the opposite buttock to expose the medial aspect of the thigh. Before applying the tourniquet, the flap is outlined over the lower medial aspect of the thigh. The pivotal point is located approximately over the palpable insertion of the adductor magnus tendon. Elevation of the flap should include the aponeurosis of the vastus medialis $m$. and is carried out from the anterior incision, identifying any and all cutaneous branches and their origin. Careful elevation of the vastus medialis $\mathrm{m}$. in a distal to proximal direction exposes the $\mathrm{OAB}$, which lies just posterior to the medial intermuscular septum. Following the $\mathrm{OAB}$ proximally to its origin, the pattern of the DGA can be determined. Depending on the anatomy and the desired length of the pedicle, one of the above-described possible pedicle types chosen. It is very important to protect the venae comitantes by leaving an adjacent strip of the medial intermuscular septum. After complete dissection of the pedicle, the skin layer is raised by com- 

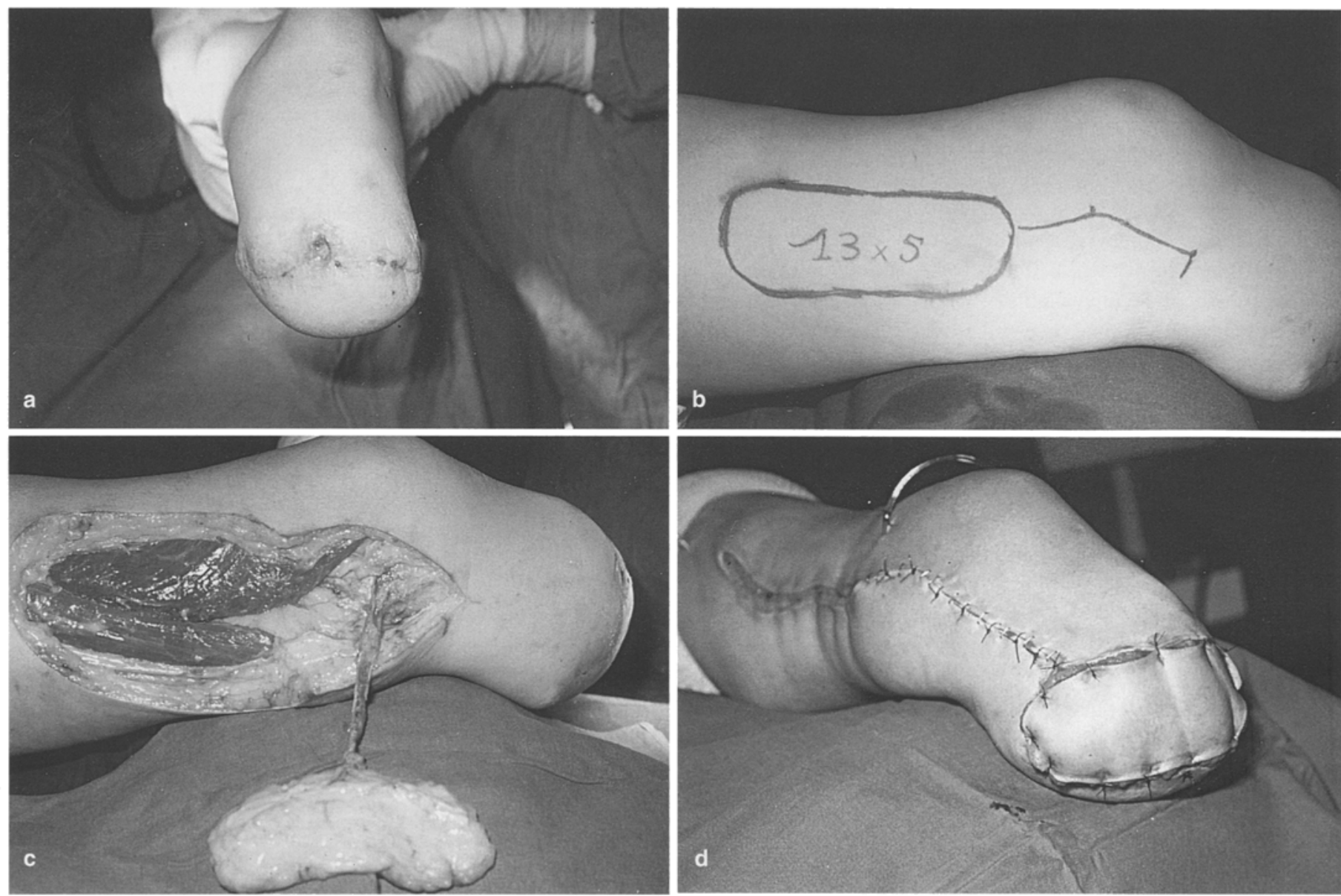

Fig. 6a-d

a Left below-knee amputation stump with a chronic pressure sore of the scar. b Outline of a $13 \times 5 \mathrm{~cm}$ island flap on the medial thigh. $\mathbf{c}$ After elevation of the fasciocutaneous flap the anastomoses of the $\mathrm{OAB}$ with the vascular network on the medial femoral condyle are visible. $\mathbf{d}$ After generous excision of the scar the stump was covered and the donor side defect primarily closed

pleting the incision of the dorsal half. The donor defect is closed directly, if the skin layer does not exceed 6-7 cm in width. The length and the flexibility of the pedicle allow rotation of the flap in various planes to perfectly fit in a defect.

\section{Clinical applications}

\section{Case 1}

A chronic pressure sore of the scar in a patient with a traumatic below-knee amputation was present (Fig. 6a). A $13 \mathrm{x}$ $5 \mathrm{~cm}$ reversed-flow fasciocutaneous island flap from the medio-distal thigh (Fig. 6b) was elevated, and the pedicle, consisting of the $\mathrm{OAB}$ and concomitant veins, was dissected distally to the anastomoses in the area of the medial femo- ral condyle (Fig. 6c). Generous excision of the unstable scar and vulnerable skin of the stump was performed (Fig. 6d). The defect of the stump was covered by rotating the flap in the frontal and axial planes. The donor site defect was closed directly. The transferred flap was well perfused. The postoperative course was uneventful, with complete flap survival.

\section{Case 2}

This patient had a patellar fracture which was approached through a longitudinal incision for open reduction and internal fixation. Postoperatively, skin necrosis developed with eventual exposure of the patella and the implants. After debridement the prepatellar defect was covered with the flap described in this article.

\section{Discussion}

Reversed-flow island flaps can be transferred from a proximal to a distal part of the extremity. Harvested from the thigh, they are thus useful to cover defects around the knee and the proximal half of the leg. To the best of our knowledge, the saphenous island flap by Torii [16], based on the original description by Acland [1], the saphenous posteromedial cutaneous island thigh flap and the saphenous superomedial cutaneous island leg flap [5], the medial septocutaneous island thigh flap [4], the sartorius myocutaneous island flap [14], the reversed-flow saphenous island flap based on the medial inferior genicular a. [17], and the adipofascial flap of the lower leg based on the saphenous a. [10] are the only reversed-flow 
fasciocutaneous island flaps of this anatomic region. All these flaps are supplied by a retrograde circulation through anastomoses of the saphenous a. with the perforating branches of the posterior tibial and medial inferior genicular aa. After previous trauma these perforators may be damaged or even absent, as in through-knee amputation. Therefore these flaps may all be unavailable.

In this article another reversed-flow fasciocutaneous island thigh flap is added to the armamentarium of the reconstructive surgeon. In contrast, this flap is supplied by reversed-flow in the osteoarticular branch of the descending genicular a. As the osteoarticular branch anastomoses with the proximal genicular anastomotic network, ie mainly the medial superior genicular a., the presence of perfused blood vessels below the level of the knee joint-line is not a prerequisite. The slender and relatively long vascular pedicle allows rotation of the flap in different planes to perfectly fit in the defect.

Most of our anatomic data on the arteries forming the DGA are in good correspondence with the literature $[4,6]$. Only the incidence of an independent origin of these vessels from the femoral a. was found to be slightly higher by Bertelli [4]. The frequency of cutaneous branches originating from the $\mathrm{OAB}$ in our dissections is consistent with the data published by Martin [11], who found in $31 / 36$ specimens $(86 \%)$ cutaneous branches from the $\mathrm{OAB}$. Therefore it is theoretically possible to raise a flap on the $\mathrm{OAB}$ alone in more than $80 \%$ of cases. But to raise the longest possible pedicle we have chosen a vascular axis formed by the $\mathrm{OAB}$ and $\mathrm{SA}$ in $33 \%$ of our specimens. In $10 \%$ of our dissections it was not possible to raise a flap based on the $\mathrm{OAB}$, or $\mathrm{OAB}$ and SA. Provided that the saphenous $a$. is retrogradely perfused by the perforating branches of the posterior tibial and medial inferior genicular aa., a reversed-flow saphenous island flap may be elevated under these circumstances (Fig. 4) [4, 5, 16, 17]. However, it must be remembered that the flap presented in this study and based on the $\mathrm{OAB}$ or $\mathrm{OAB}$ and $\mathrm{SA}$ is not dependent on perfused blood vessels below the level of the joint-line of the knee.
Other methods for closure of defects around the knee, if flaps below the knee are unavailable, have been described. The distally based vastus lateralis muscle flap [13] is bulky and delayed skin grafting due to superficial muscular necrosis has been observed by the authors. The vastus medialis $m$. as a rotation flap [2] covers only defects in the upper part of the knee and the vastus medialis myocutaneous/ myocutaneous-tendinous advancement flap [15] is useful only for small defects. If muscle flaps are used one should consider the degree of functional loss. The popliteo-posterior island [12] and posterolateral thigh flaps [9] are similar fasciocutaneous flaps, but require the lateral or prone position, which may be a disadvantage in anterior soft tissue defects. Free tissue transfer [7] is complicated, less economical and requires microsurgical expertise. The cross-leg flap [3] is a multi-stage procedure and the lower extremities are immobilized in an uncomfortable position over an extended time.

\section{Conclusion}

We believe that the reversed-flow fasciocutaneous island flap raised on the $\mathrm{OAB}$, or on the $\mathrm{OAB}$ and $\mathrm{SA}$, has some advantages and will be a valuable addition to the armamentarium of procedures for coverage of soft-tissue defects around the knee and proximal half of the leg, when muscular or fasciocutaneous flaps from the calf are not otherwise available.

Acknowledgments This work was supported by a grant from the Swiss Orthopaedic Society (SGO), by the Department of Orthopaedic Surgery, Inselspital, University of Berne (Switzerland) and by the Laboratory of Anatomy, René Descartes University, Paris (France).

\section{References}

1. Acland RD, Schusterman M, Godina M, Eder E, Taylor GI, Carlisie I (1981) The saphenous neurovascular free flap. Plast Reconstr Surg 67: 763-774

2. Arnold PG, Prunes-Carrillo F (1981) Vastus medialis muscle flap for functional closure of the exposed knee Joint. Plast Reconstr Surg 68: 69-72

3. Barclay TL, Sharpe DT, Chisholm EM (1983) Cross-leg fasciocutaneous flaps. Plast Reconstr Surg 72: 843-846
4. Bertelli JA (1992) The medial septumcutaneous island thigh flap (25.10.91). Surg Radiol Anat 14: 191-192

5. Bertelli JA (1992) The saphenous posteromedial cutaneous island thigh flap and the saphenous supero-medial cutaneous island leg flap (25.10.91). Surg Radiol Anat 14: 187-189

6. Hertel R, Masquelet AC (1989) The reversedflow medial knee osteoperiosteal flap for skeletal reconstruction of the leg. Description and anatomical basis. Surg Radiol Anat 11:257-262

7. Kasabian AK, Colen SR, Shaw WW, Pachter HL (1991) The role of microvascular free flaps in salvaging below-knee amputation stumps: A Review of 22 Cases. J Trauma 31 : 495-501

8. Kirschner MH, Menck J, Hofmann GO (1996) Anatomic bases of a vascularized allogenic knee joint transplantation: arterial blood supply of the human knee joint. Surg Radiol Anat 18: 263-269

9. Laitung JKG (1989) The lower posterolateral thigh flap. Br J Plast Surg 42: 133-139

10. Lin SD, Lai CS, Chiu YT, Lin TM, Chou CK (1996) Adipofascial flap of the lower leg based on the saphenous artery. Br J Plast Surg 49: 390-395

11. Martin D, Bitonti-Grillo C, De Biscop J, Schott $\mathrm{H}$, Mondie JM, Baudet J, Peri G (1991) Mandibular reconstruction using a free vascularised osteocutaneous flap from the internal condyle of the femur. Br J Plast Surg 42: 397-402

12. Maruyama X, Iwahira Y (1989) Popliteo-posterior thigh fasciocutaneous island flap for closure around the knee. Br J Plast Surg 42: 140-143

13. Swartz WM, Ramasastry SS, McGill JR, Noonan JD (1987) Distally Based Vastus Lateralis Muscle Flap for Coverage of Wounds About the Knee. Plast Reconstr Surg 80: 255-263

14. Tang ML, Liu XY, Ren JW, Zhang DC, Li RS, Wen YM, Ge BF (1993) The sartorius myocutaneous island flap. Surg Radiol Anat 15: 259-263

15. Tobin GR (1985) Vastus Medialis Myocutaneous and myocutaneous-tendinous composite flaps. Plast Reconstr Surg 75: 677-684

16. Torii $S$, Hayashi $Y$, Hasegawa $M$, Sugiura $S$ (1989) Reversed-flow saphenous island flap in the patient with below-knee amputation. $\mathrm{Br}$ J Plast Surg 42: 517-520

17. Tsai CC, Lin SD, Lai CS, Chou CK, Lin TM (1995) Reconstruction of the upper Leg and knee with a reversed flow saphenous island flap based on the medial inferior genicular artery. Ann Plast Surg 35: 480-484

18. Williams PL, Warwick R, Dyson M, Bannister LH (1989) Gray's anatomy. Churchill Livingstone, Edinburgh London Melbourne New York

Received February 23, 1998 / Accepted in final form July 7, 1998 